\title{
A Four-Year Prospective Study of Injuries in Elite Ontario Youth Soccer Players During Training and Match Play: A Follow-Up
}

\author{
Robert Gringmuth* \\ Ontario Soccer Centre, Canadian Memorial College, Canada
}

*Corresponding author: Robert Gringmuth, Canadian Memorial Chiropractic College, 6100 Leslie Street, Toronto, M2H 3J1, Canada. (or) Sports Injury \& Rehabilitation Centre, Inc. 1210 King's College Drive, Oakville, L6M 2S5, Canada.
Received Date: March 20, 2020

Published Date: April 13, 2020

\begin{abstract}
Introduction: With over 200 million amateur athletes worldwide, with soccer as one of the most popular and internationally recognized sports today. By understanding how and why soccer injuries occur, we hope to reduce prevalent injuries amongst soccer athletes.

Methods: Via a prospective cohort, we tracked male and female soccer players between the ages of 13 to 17 eligible to train with the Ontario Soccer Association provincial program during the period of January 1st, 2013 and December 31st, 2016. Data collection occurred during all player exposures to potential injury. Exposures occurred at the Ontario Soccer Centre training grounds and various other venues on multiple playing surfaces throughout Ontario. injury.

Results: 473 injuries were recorded. Muscle strain, pull or tightness was responsible for $35.7 \%$ of all injuries and ranked as the most prevalent

Discussion: As anticipated, the most common injury reported in a four-year prospective study of injuries in elite Ontario youth provincial and national soccer players during training and match play was muscular strain, which warrants more suitable preventive programs aimed at strengthening and properly warming up the players' muscles.
\end{abstract}

Keywords: Soccer; Injury; Athlete; Youth; Muscle strain; Epidemiology; Prevalence; Incidence

\section{Introduction}

It is estimated that there are some 200 million amateur soccer players and approximately 200,000 professional athletes worldwide, soccer is one of the most popular and internationally recognized sports played today. The 2014 Fédération Internationale de Football Association (FIFA) World Cup in Brazil was one of the most watched television events in history [1]. A total of 3.43 million people watched 64 games, meaning the average attendance per game was 53,592. This was the highest average since the 1994 World Cup in the United States. As of 2014 [2], there were approximately 270 million active player memberships to FIFA.

In considering the various aspects of the game, player safety is first and foremost considered the responsibility of the participants and organizers. With many sports being played, injuries are inevitable as the potential for injuries increases with intensity, frequency, and vigor of the training sessions. As reported by
Schmikli SL, et al. [3] the incidence rate of outdoor soccer injuries, particularly for adult male soccer players, is among the highest of all sports including rugby, boxing, fencing, and cricket. Although there is some discrepancy in reports of the number of injuries per 1,000 playing hours, according to Goncalves CA, et al. [1] the incidence of soccer related injuries is estimated to be 10 to 15 injuries per 1,000 hours of practice. Dvorak J, et al. [4] found similar statistics, reporting 12 to 35 injuries per 1000 match hours, and 1.5 to 7.6 injuries per 1000 training hours. Injury avoidance is a crucial element for the youth soccer athlete at all competitive levels. This allows athletes to train and develop their skill sets at their maximal effort without avoidable layoffs. Time loss due to injury is critical for both a promising soccer athlete and their team due to injury limiting the possibility of the team reaching its highest performance potential. There is an estimated time loss due to injury of two weeks for a team made up of 25 players. 
Injury has a negative economic impact on both the athlete and the team. There are long-term consequences associated with being injured as an athlete. FIFA estimates that the average treatment cost is $\$ 150$-U.S. per injury, which leads to an estimated $\$ 30$ billion U.S. a year for treatment of injuries in soccer around the world [2]. In addition, English Premier League clubs were estimated to be $\$ 19$ to 26 million-U.S. out-of-pocket in lost wages due to injuries suffered by their players in the 2010/11 season after taking part in the World Cup [5].

It is evident that injury prevention plays a necessary role in reducing the costs incurred from soccer-related injuries along with minimizing a player's time loss due to injury. Prevention is usually seen as the first step in maintaining optimal health. With injury prevention we must understand the types of injuries and their mechanisms that are common amongst soccer athletes. The consensus is that the majority of soccer injuries are related to the lower extremities, which is not surprising since soccer is a highintensity sport characterized by continuous changes of direction and high-load actions [6]. Nonetheless, in various soccer nations, such as the United Kingdom, the United States and Brazil, the epidemiology of injuries within the sport has shown a variation in injury patterns. For instance, the Carling et al. study suggested strains to the hamstring region are the most common type of injury at the professional levels in soccer [7]. Research studies suggest eccentric strength training can reduce the risk of hamstring injury in heterogeneous populations of soccer players [8]. In addition, plyometric training and agility drills, the main components of a preventive program developed by Heidt RS Jr, et al. [9] were effective in lowering the incidence of injuries in soccer. The Dick R, et al. [10] study concluded ankle ligament sprains, knee internal derangements and concussions are common injuries in women's soccer. Ekstrand J, et al. [11] determined that almost one-third of all injuries in professional soccer are muscle injuries with the vast majority affecting the hamstring, adductors, quadriceps and calf muscles [11]. Therefore, it will be difficult to correlate the reported injury incidence, and thus formulate effective injury prevention strategies, for elite soccer athletes outside the geographic domain in which the study was conducted. To date, an epidemiological study has not been conducted regarding elite youth soccer athletes in Canada aside from our previous study.

According to Aaltonen S, et al. [12] decreased risk of sports injuries was associated with the use of insoles, external joint supports, and multi-intervention training programs. A paper by Emery CA \& Meeuwisse WH [13] found that an implemented training program was effective in reducing the risk of all injuries as well as preventing injuries. The protective effect of the neuromuscular training program in reducing lower extremity injury is clinically relevant. Finally, Dvorak J \& Junge A [4] showed that there is some evidence that multi-modal intervention programs result in a general reduction in injuries. They found that external ankle supports and proprioceptive/coordination training, especially in athletes with previous ankle sprains, could prevent ankle sprains. In addition, training of neuromuscular and proprioceptive performance as well as improvement of jumping and landing technique seems to decrease the incidence of anterior cruciate ligament injuries in female athletes [14].

Therefore, it will be difficult to correlate injury incidence and thus injury prevention for youth soccer athletes outside the geographic domain in which the study was conducted. To date such a study has not been conducted within the scope of elite youth soccer athletes in Canada. The variability of the conclusions of these studies likely reflects that there are many factors (i.e. location, weather, surface playing field, age, sex and performance level) that ultimately determine the variation on why and how soccer players are injured and in turn, the preventative strategies that can be utilized to help reduce both the occurrence and recurrence of such injuries.

By taking into consideration the model for epidemiological studies on professional soccer player injuries in Brazil [1], the purpose of this preliminary study is to provide an injury incidence report for youth soccer in both Ontario as well as nationally in Canada. As such, due to differences in climate, technical level and total hours of play and training we believe that occurrence of injury per 1,000 hours of play and training, will be less in Canada compared to other soccer nations. The second objective is to provide an injury incidence report for the most common injuries during training and match play among youth soccer players in Ontario. By understanding how and why soccer injuries occur we ultimately hope to reduce the most prevalent injuries amongst youth Canadian soccer athletes beginning with an incidence inventory as a necessary first step.

\section{Research Design and Methods}

In concordance with Goncalves CA, et al. [1] the research design selected for this study is a prospective cohort. Historically, epidemiological studies examining soccer injury incidence have been prospective in nature. Methodology utilizing retrospective study design had many biases, which reduced the validity of risk assessments. Prospective study design has been shown to be the most useful method for estimating the risk of injury or disease, the incidence rate and/or relative risk [7].

Through a prospective concurrent longitudinal study, we can determine and define the population at the beginning of the study and follow the subjects through time. Cases are enrolled from a well-defined population, current exposure status is determined as non-injured and the onset of injury is observed in subjects over time. Injury status can be compared to non-injured status relative to exposure time. The study begins at the exposure of the cohort to exposure. Exposure status has been predetermined as all strength and conditioning sessions, training sessions and games overseen by an athletic therapist. The characteristics of the group of people studied have been pre-determined as healthy eligible Ontario Soccer Association (OSA) provincial and National Training Centre Ontario (NTCO) players. Non-cases or uninjured eligible players are 
followed forward in time. Cases or injury status and recording of the aforementioned have also been pre -determined.

The population of this study included all soccer players, males and females, between the ages of 13 to 17 years, eligible to train with the Ontario Soccer Association provincial program during the period of January 1, 2013 to December 31, 2016. It also included all players eligible to play for the NTCO Under-17 women's program during the aforementioned periods. The players were selected based on criteria determined by the Ontario Soccer Association coaches and are considered among the elite population of soccer players in the province and country. In total, the study worked with seven teams each 28 players per team through four calendar seasons which runs from mid-October until the end of April of the following year. The total exposure hours were calculated combining training, match and strength conditioning hours for one calendar year or the provincial program from mid-October until the end of April. The exposure hours were then extrapolated over four years due to the consistency in scheduling within the provincial program related to limitations in field time. A total of 32,270 hours of exposure were recorded over one calendar year and estimated as 129,080 hours over four years.

\section{Collection of Data}

The source of data collection is The Sports Injury \& Rehabilitation Centre, Inc. (SIRC). All player injuries were tracked and recorded on site using the centre's electronic medical recording database called Injury Tracker ${ }^{\circledR}$. Data collection occurred during all player exposures to potential injury including strength and conditioning sessions, training sessions and matches. Exposures occurred the Soccer Centre, Ontario training grounds and various other venues on various playing surfaces. An athletic therapist employed by SIRC oversaw all exposures. Injury reports were filled out by a healthcare provider at occurrence of injury and before a player is referred for follow up medical care. An injury report is required to be completed if any of the following criteria are met:

-Player is removed from field of play by a health care provider or player is unable to return to play.

-Player requires treatment to return to play.

-Player suffers a concussion.

-Player does not participate in practice due to injury/condition.

-Player intake at the clinic directly due to inability to play.

Injury reports are submitted at the end of the session by the healthcare provider to the clinic supervisor who ensures that designated clinic personnel enters them into the clinic database.

\section{Ethics and Human Subjects Issues}

Players' names or personal medical information cannot be tracked or identified in any manner.

\section{Results}

A total of 473 injuries were recorded through 129,080 exposure actual hours experienced by seven teams over the span of four seasons. The cumulative injury incidence rate among all players through four seasons was 8.34 injuries per 1,000 hours of training, strength and conditioning, or match play. The highest injury incidence rate occurred during the 2013 to 2014 season valued at 11.62 injuries per number of hours trained and played. The seasonal injury incidence variation across four years is presented in Figure 1.

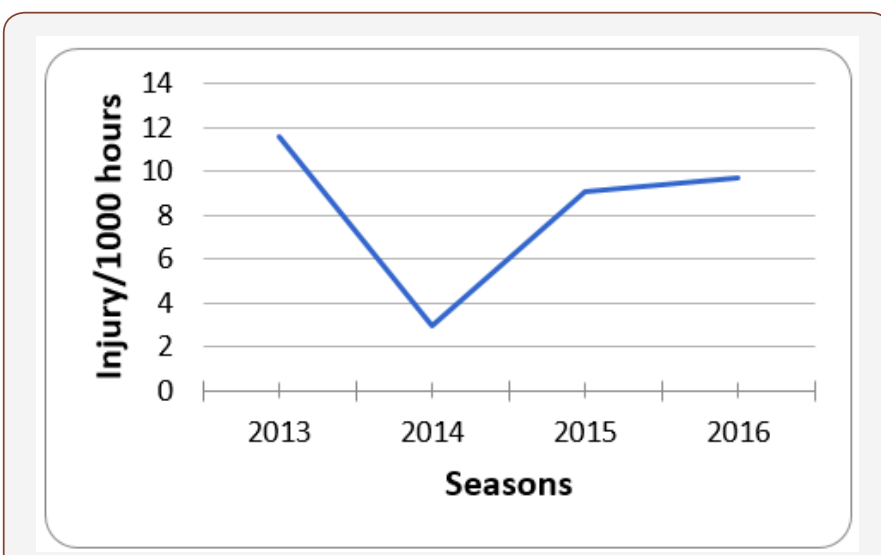

Figure 1: Injury incidence of youth provincial and national soccer players in Ontario per 1,000 hours of exposure over four seasons.

Myofascial pain resulting from muscle strain, pull, or tightness was responsible for $35.7 \%$ of all injuries. It was ranked as the most prevalent of all diagnosed soft tissue injuries with an incidence rate of 9.75 occurrences per 1,000 hours. Ligamentous sprain comprised $28.3 \%$ of all injuries ranking it the second most common injury presented. Its incidence rate was 7.73 injuries per 1,000 hours. Sprain and strain injuries comprised $64 \%$ of total injuries incurred. Concussion injuries consisted of $13.7 \%$ of total injuries and had an incidence rate of 3.74 per 1,000 hours.

Other common injuries reported include bleeding, lacerations, abrasions, blisters, and fractures. The most prevalent diagnosed injuries and their incidence rates per 1,000 hours are presented in Table 1.

The most commonly injured body part across all four years was the ankle/foot complex. It comprised $23.6 \%$ of all injuries over four years and had an incidence rate of 1.3 per 1,000 hours. The knee was the second most common area of injury across all seasons. The knee comprised $14.5 \%$ of total injuries and had a reported incidence rate of 0.77 injuries per 1,000 hours. Muscle injuries to the quadriceps, hamstring and groin were the third most common injuries comprising a combined $10.4 \%$ of injuries and incidence rate of 0.56 injuries per 1,000 hours. Injuries of the lower leg complex consisted of the achilles, shin and calve injuries. Comprising 5.8\% of total injuries with an injury incidence rate of 0.3 lower extremity injuries encompassed $91 \%$ of total injuries and had an incidence rate of 4.9 per number of hours. 
Table 1: Incidence of most diagnosed injuries between January 1, 2013 to December 31, 2016.

\begin{tabular}{|c|c|c|c|}
\hline & $\mathbf{n}$ & $\%$ & Incidence \\
\hline Sprains & 134 & 28.3 & 9.73 \\
\hline Muscle strain/pull/tightness & 169 & 35.7 & 2.02 \\
\hline Fractures & 35 & 7.4 & 3.74 \\
\hline Concussions & 65 & 13.7 & 1.677 \\
\hline Blisters & 7 & 6.1 & 2.6 \\
\hline Bleeding/lacerations/abrasions & 37 & 9.5 & 0.301 \\
\hline Separation of joint & 2 & 1.1 & 0.191 \\
\hline Bunion of the big toe & 0 & 0.7 & 0.06 \\
\hline Common cold & 1 & 0.2 & 0.14 \\
\hline Asthma causing symptoms with & 5 & 0.5 & 0.63 \\
\hline participation & 11 & 2.3 & 0.14 \\
\hline Plantar fasciitis & 0 & 0.5 & 0.191 \\
\hline Poked in eye & 1 & 0.7 & 0.27 \\
\hline Turf toe & 1 & 1 & 0 \\
\hline Avulsion fracture & 0 & 0 & 0.22 \\
\hline Achilles tendonitis & 4 & 0.8 & 0.06 \\
\hline Hyperextension of unspecified joint & 1 & 100 & 3.66 \\
\hline Joint instability & 473 & 0.2 & \\
\hline Total & & & \\
\hline
\end{tabular}

\section{Discussion}

As mentioned earlier it will be difficult to correlate injury incidence and thus injury prevention for elite soccer athletes outside the geographic domain in which the study was conducted. To date such a study has not been conducted within the scope of elite soccer athletes in Canada. With the increasing growth and development in the sport of soccer in Canada, risk of injury during training and gameplay can be a deciding factor on how young elite Canadian athletes compete with their peers from competing soccer nations. In order to help determine the incidence or risk of injury, there are two things that need to be defined: the definition of an injury and the standard measure for reporting soccer related injuries. The term 'injury' in its relation with soccer is currently defined as anything that incapacitates a soccer player from full participation in imminent training or matches [3]. Moreover, the standard measure for reporting the incidence of soccer related injuries is determined by how long an individual athlete is exposed to the possibility of an injury. Thus the measure is the number of injuries per 1,000 hours of soccer participation (i.e. practice, training, and game play) [1].

Table 2: Prevalence of injury location and injury incident rate per 1,000 hours.

\begin{tabular}{|c|c|c|c|c|c|c|c|c|c|c|c|c|}
\hline \multirow[b]{2}{*}{ Body part } & \multicolumn{3}{|c|}{2013 to 2014} & \multicolumn{3}{|c|}{2014 to 2015} & \multicolumn{3}{|c|}{2015 to 2016} & \multicolumn{3}{|c|}{2016 to 2017} \\
\hline & $\mathrm{n}$ & $\%$ & Incidence & $\mathrm{n}$ & $\%$ & Incidence & $\mathrm{n}$ & $\%$ & Incidence & $\mathrm{n}$ & $\%$ & Incidence \\
\hline Ankle/foot & 105 & 28 & 3.25 & 41 & 42.71 & 1.27 & 57 & 19.39 & 1.77 & 78 & 25 & 2.42 \\
\hline Knee & 69 & 18.4 & 2.14 & 17 & 17.71 & 0.53 & 48 & 16.33 & 1.49 & 48 & 15.38 & 1.49 \\
\hline Quadriceps & 12 & 3.2 & 0.37 & 4 & 4.17 & 0.28 & 17 & 5.78 & 0.53 & 16 & 5.13 & 0.5 \\
\hline Hamstrings & 20 & 5.33 & 0.62 & 4 & 4.17 & 0.19 & 7 & 2.38 & 0.22 & 13 & 4.17 & 0.4 \\
\hline Groin/adductors & 19 & 5.07 & 0.59 & 2 & 2.08 & 0.31 & 8 & 2.72 & 0.25 & 10 & 3.21 & 0.31 \\
\hline Head/face & 22 & 5.86 & 0.68 & 7 & 7.29 & 0.5 & 49 & 16.67 & 1.52 & 61 & 19.55 & 1.89 \\
\hline Neck/back & 16 & 4.26 & 0.5 & 6 & 6.25 & 0.22 & 31 & 10.54 & 0.96 & 28 & 8.97 & 0.87 \\
\hline
\end{tabular}

Our study concluded that the total injury incidence rate over all exposures was 3.66 injuries per 1,000 hours. This rate is far less than what is reported from Hassabi M, et al. [15] who conducted a 15 year epidemiological study on injuries during official Japanese professional soccer league matches. The study had a relatively high incidence rate ranging from about 11 to 24 injuries per 1,000 hours, but this is significantly higher than a study conducted by Le Gall F, et al. [16] on elite French youth soccer players which reported an overall injury rate ranging from 4.6 to 5.3 injuries per 1,000 hours. Our results are comparable to other studies conducted on youth soccer players, which reported incidences ranging from 0.535 to 5.640 injuries per 1,000 hours [16]. Furthermore, common injury sites in our study compare with those of participants in the study by Le Gall et al. A study of elite English academy players identified muscle strain, sprain and pull or tightness with $(66.34 \%, 62.5 \%$ and $66 \%$ respectively) as the most prevalent injury [17]. An increase in reported concussions were seen in this 4-year period as compared to those reported in our previous study [18], more than likely due to increase in reporting and awareness [19] (Table 2). 


\begin{tabular}{|c|c|c|c|c|c|c|c|c|c|c|c|c|}
\hline $\begin{array}{c}\text { Shoulder/arm/ } \\
\text { hand/fingers }\end{array}$ & 25 & 6.67 & 0.78 & 4 & 4.17 & 0.28 & 27 & 9.18 & 0.84 & 15 & 4.81 & 0.47 \\
\hline $\begin{array}{c}\text { Lower leg/ } \\
\text { achilles/shin/calf }\end{array}$ & 59 & 15.74 & 1.83 & 11 & 11.46 & 0.74 & 40 & 13.61 & 1.24 & 23 & 7.37 & 0.71 \\
\hline Toes & 7 & 1.87 & 0.22 & 0 & 0 & 0 & 5 & 1.70 & 0.15 & 5 & 1.6 & 0.15 \\
\hline Hip & 21 & 5.6 & 0.65 & 0 & 0. & 0.22 & 5 & 1.70 & 0.15 & 15 & 4.81 & 0.46 \\
\hline Total & 375 & 100 & 11.62 & 96 & 100 & 2.97 & 294 & 100 & 9.11 & 312 & 100 & 9.67 \\
\hline
\end{tabular}

The shortcomings of conducting a prospective cohort study include changes in methodology for detecting or recording injury due to the length of study period. In this specific study inter-examiner variability exists between the various healthcare providers. Although they are trained to follow protocol, their diagnostic impressions of the injuries can affect reported findings. Exact exposure hours are unattainable, as attendance was not taken during all sessions. Therefore, exposure hours are calculated based on the assumption that all players were present for all training sessions and games, which is not always the case. There is then an assumption those exposure hours will be overestimated. This would inflate the denominator of the incidence ratio and suggest a lower incidence than actually occurred. In addition, the study did not look at how the exposure time was split between time spent training and time spent during games. By differentiating match play and training we can make conclusions as to whether overtraining may be the cause of injury or if match intensity results in higher injury rates.

The strengths of this study include the sample size of the study, the study duration and the elite status of the athletes. Few studies have followed as many elite athletes, over as many exposure hours, at such a high level of competition. Due to the size and methodology of the study, conclusions can be made with sufficient empirical evidence and validity.

Future recommendations for improving data collection/data analysis are to include the following: whether injury was due to contact, foul play or spontaneous occurrence; the time of the injury occurrence; player's position; and prior injuries. Noting how an injury arose can be a useful tool in understanding how to prevent the same injury from reoccurring. With players forcefully colliding for the soccer ball, pushing for positioning during a corner kick and receiving or delivering a tackle or charge, there can be various moments in which a player can get injured due to physical contact or foul play [12]. As noted during the 2014 World Cup, it was reported that $64.4 \%$ of the injuries occurred during contact play [2].

The time of injury can also be a useful tool to use. There have been many studies with various results on when injuries do in fact occur. Wong P \& Hong Y [8] reported that there was a difference between the incidence of injury with each 15-minute segment in a game compared to 45-minute halves, whereas Rahnama N, et al. [20] reported those mild injuries occur during the first 15-minute segments of each half and that moderate injuries occur during the last 15-minute segment of the game. Dick R, et al. [10] reported that the risk of injury is the highest during the first and last 15 minutes of game play. Since there is no precise time for when injuries occur in soccer matches, further studies should be conducted to determine an estimated time for when Canadian soccer athletes are most likely to sustain injuries.

Consideration of the player's position is also a factor that can be analyzed. Was the player injured playing their regular position or a different one due to external circumstances? After discussion with the coach, players usually settle on their particular position for the season, and barring any unforeseen circumstances they stick with that position throughout the season. Moreover, another factor that can be analyzed is which position gets injured more. Elite youth defenders are injured more often than their fellow teammates during competition, whereas the injury rate for goalkeepers account for only $6 \%$ of all player injuries in adult professional soccer games [16]. These results show that the physical demands for each position vary and thus may account for the frequency and also type of injury Canadian soccer players may face. Lastly, prior injury is a factor that can be used to help improve the analysis of this study. Reinjures can cause 30\% longer absence from game play, thus knowing whether there is history of injury can help evaluate the risk and scope of training needed [10]. As noted prior injury can increase the risk of future injuries and thus a proper evaluation is needed by teams to determine whether a player is susceptible to a particular injury. In addition, if a player has a history of a specific reoccurring injury, rehab programs can be analyzed to see what can be improved in order to prevent the injury from occurring again.

The occurrence of injuries in high-level soccer players is most likely multifaceted. Volpi P \& Taioli E [17] noted several external, personal, and behavioral risk factors likely associated with injuries, as well as the risk factors which can be avoided or prevented through appropriate interventions. Over the past years, the intensity and speed of both training and game play along with the players' skill level and experience are hypothesized to be contributing factors to the type and number of injuries registered [17-19]. Another risk factor that has been noted is the ratio of time spent training to playing in games. Less time available for appropriate training was noted to be a good indicator of injuries in soccer players. A few factors have been identified, but have not been fully addressed to our knowledge, including environmental factors, such as training and playing surfaces, field conditions at the time of injuries and type of shoes worn. Another predictor is the amount of time spent playing between players. This means that in high level teams coaches are more prone to select the best players to play larger number of minutes during a game sometimes overworking these individuals [20-25]. 


\section{Conclusion}

This study sheds light on the number and varying types of injuries sustained by elite Canadian youth soccer players, however it fails to address certain issues that need to be looked at in the future, which include predictors in behavioral, environmental, and physical injury predictors in soccer. However, some practical applications can be drawn from what was found, such as the fact that muscular strains, pulls and tightness were the most commonly found injury of soccer players. Thus, an appropriate strengthening program and proper implementation of warm-up and cool down exercises before training and matches can potentially reduce the number of muscular strain occurrences.

Results from this study on injury rates of elite Canadian youth soccer athletes revealed what was suspected for occurrence over 1000 exposure hours in comparison to major soccer countries. The highest injury reported was muscular strain, which warrants more suited preventative programs aimed at strengthening and properly warming up the players' muscles. Also, as noted by several other soccer injury studies, Wong P \& Hong Y [8] identified the knee and secondly the ankle region as the area of highest sustained injuries, suggesting prospective intervention studies to evaluate an injury prevention protocol. This study is specifically important to the Canadian Soccer Association, the Ontario Soccer Association and its respective healthcare providers. Identifying an epidemiological model for injury incidence is important in understanding how injury develops. Then, preventative programs can be designed to enhance the growth and development of amateur and elite Canadian soccer.

\section{Acknowledgment}

The Frank Markus, Igor Steiman, Yi Liu, Serhiy Marchak, Edward Nigro, B Kin, Keith Leung and BA Kin are equally contributed.

\section{Conflict of Interest}

Author declare no conflict of interest.

\section{References}

1. Goncalves CA, Belangero PS, Runco JL, Cohem M (2001) The Brazil Football Association (CBF) model for epidemiological studies on professional soccer player injuries. Clin Sci 66 (10): 1707-1712.

2. FIFA. Previous FIFA World Cups.

3. Schmikli SL, de Vries WR, Inklaar H, Back FJ (2011) Injury prevention target groups in soccer: Injury characteristics and incidence rates in male junior and senior players. J Sci Med Sport 14(3): 199-203.

4. Dvorak J, Junge A (2000) Football injuries and physical symptoms: A review of the literature. Am J Sports Med 28(5 Suppl): S3-S9.

5. Clubs count the cost of world cup injuries.

6. Wong P, Hong Y (2005) Soccer injury in the lower extremities. Br J Sports Med 39(8): 473-482.

7. Carling C, Gall FL, Orhant E (2011) A four-season prospective study of muscle strain reoccurrences in a professional football club. Res Sports Med 19(2): 92-102.
8. Arnason A, Andersen TE, Holme I, Engebretsen L, Bahr R (2008) Prevention of hamstring strains in elite soccer: an intervention study. Scand J Med Sci Sports 18(1): 40-48.

9. Heidt RS Jr, Sweeterman LM, Carlonas RL, Traub JA, Tekulve FX (2000) Avoidance of soccer injuries with preseason conditioning. Am J Sports Med 28(5): 659-662.

10. Dick R, Putukian M, Agel J, Evans TA, Marshall SW (2007) Descriptive epidemiology of collegiate women's soccer injuries: National Collegiate Athletic Association Injury Surveillance System, 1988-1989 through 2002-2003. J Athl Train 42(2): 278-285.

11. Ekstrand J, Hagglund M, Walden M (2011) Epidemiology of muscle injuries in profession football (soccer). Am J Sports Med 39(6): 12261232

12. Aaltonen S, Karjalainen H, Heinonen A, Parkkari J, Kujala UM (2007) Prevention of sports injuries: systematic review of randomized controlled trials. Arch Intern Med 167(15): 1585-1592.

13. Emery CA, Meeuwisse WH (2010) The effectiveness of a neuromuscular prevention strategy to reduce injuries in youth soccer: a clusterrandomised controlled trial. Br J Sports Med 44(8): 555-562.

14. Junge A, Dvorak J (2004) Soccer injuries: a review on incidence and prevention. Sports Med 34(13): 929-938.

15. Hassabi M, Mortazavi MJ, Giti MR, Hassabi M, Mansournia MA, et al. (2010) Injury profile of a professional soccer team in the Premier League of Iran. Asian J Sports Med 1(4): 201-208.

16. Le Gall F, Carlin C, Reily T, Vadewalle H, Church J, et al. (2006) Incidence of injuries in elite French youth soccer players. Am J Sports Med 34(6): 928-938.

17. Volpi P, Taioli E (2012) The health profile of professional soccer players: future opportunities for injury prevention. J Strength Cond Res 26(12): 3473-3479.

18. Mohib M, Moser N, Kim R, Thailai M, Gringmuth R (2014) A Four Year Prospective Study of Injuries in Elite Ontario Youth Provincial and National Soccer Players during Training and Matchplay. J Can Chiropr Assoc 58(4): 369-376.

19. Kazemi M, Pieter W (2004) Injuries at a Canadian National Taekwondo Championships: a prospective study. BMC Musculoskeletal Disord 5: 2230 .

20. Rahnama N, Reilly T, Lees A (2002) Injury risk associated with playing actions during competitive soccer. Br J Sports Med 36(5): 354-359.

21. Collins CL, Fletcher EN, Fields SK, Kluchurosky L, Rohrkemper MK, et al. Neck Strength: A Protective Factor Reducing Risk for Concussion in High School Sports. J Prim Prev: 35(5): 309-319.

22. Bianco A, Spedicato M, Petrucci M, Messina G, Thomas E, et al. (2016) A Prospective Analysis of the Injury Incidence of Young Male Professional Football Player on Artificial Turf. Asian J Sports Med 7(1): e28425.

23. Read P, Oliver J, Croix S, Myer GD, Lloyd RS (2018) An audit of injuries in six English professional soccer academies. J Sports Sci 36(13): 15421548.

24. Pfirrmann D, Herbst M, Ingelfinger P, Simon P, Tug S (2016) Analysis of Injury Incidences in Male Professional Adult and Elite Youth Soccer Players: A Systematic Review. J Athl Train 51(5): 410-424.

25. Nilsson T, Hafsteinsson OA, Alricsson M (2016) Injury profile among elite male youth soccer players in a Swedish first league. J Exerc Rehabil 12(2): 83-89. 